\title{
COMPRESSIVE DEFORMATION BEHAVIOR OF THICK MICRO-ALLOYED HSLA STEEL PLATES AT ELEVATED TEMPERATURES
}

\begin{abstract}
The hot deformation behavior of a heavy micro-alloyed high-strength low-alloy (HSLA) steel plate was studied by performing compression tests at elevated temperatures. The hot compression tests were carried out at temperatures from $923 \mathrm{~K}$ to $1,223 \mathrm{~K}$ with strain rates of $0.002 \mathrm{~s}^{-1}$ and $1.0 \mathrm{~s}^{-1}$. A long plateau region appeared for the $0.002 \mathrm{~s}^{-1}$ strain rate, and this was found to be an effect of the balancing between softening and hardening during deformation. For the $1.0 \mathrm{~s}^{-1}$ strain rate, the flow stress gradually increased after the yield point. The temperature and the strain rate-dependent parameters, such as the strain hardening coefficient $(n)$, strength constant $(K)$, and activation energy $(Q)$, obtained from the flow stress curves were applied to the power law of plastic deformation. The constitutive model for flow stress can be expressed as $\sigma=(39.8 \ln (Z)-716.6) \cdot \varepsilon^{(-0.00955 \ln (Z)+0.4930)}$ for the $1.0 \mathrm{~s}^{-1}$ strain rate and $\sigma=(19.9 \ln (Z)-592.3) \cdot \varepsilon^{(-0.00212 \ln (Z)+0.1540)}$ for the $0.002 \mathrm{~s}^{-1}$ strain rate.
\end{abstract}

Keywords: Alloys, Rolling, Strain rate, Compression test, HSLA steel

\section{Introduction}

Recently many light-weight, high strength materials have been developed for use in various applications in the automotive industry due to the current demand for fuel efficiency improvements and emissions reductions in vehicles [1-3]. Large, heavy components are still used for the chassis and body parts of commercial vehicles, and small, light components are increasingly used for passenger vehicles. Forged parts are currently being substituted with hot pressed components in order to reduce the weight of commercial vehicles, and therefore, the hot deformation behavior of high-strength steel plates has been studied. Highstrength steels can be plastically deformed at high temperatures in order to ensure high formability as well as high dimensional accuracy. $\mathrm{Nb}$-Ti-V micro-alloyed steel plate is made of one of the best candidate materials for use in automotive applications because this material has excellent weldability and high strength. The parameters used for the hot forming process, such as the temperature and the strain rate, can further influence the microstructure and the mechanical properties of the materials.

Finite element analysis (FEM) is a powerful tool that can be used to study forming processes, and it can provide an accurate prediction of the proper flow stress to be applied to the material during deformation [4]. The material model for FEM usually describes flow stress as a function of the deformation conditions, and the accuracy of the model depends on the math- ematical structure and on the proper experimental determination of the material parameters [5]. However, the flow stress model of micro-alloyed steel at elevated temperatures has only been considered in a few studies. Furthermore, the relevant flow stress models have been constructed using tensile tests and have been presented by performing a simple calculation from experimental data of the strain hardening coefficient $(n)$ and strength coefficient $(K)$.

In this study, the results of the compression test were used to construct the flow stress curve of Nb-Ti-V micro-alloyed steel, and an analytical method was used to establish a flow stress model. During compressive deformation, $n$ and $K$ are both dependent on the temperature and strain rate, and therefore, $n$ and $K$ are both related to the Zener-Holloman parameter $(Z)$, which is a temperature-compensated strain rate. The relation of $n$ and $K$ with $\ln (Z)$ was found to follow a linear curve, and the flow stress model was expressed by introducing $\mathrm{Z}$ to the power law model while analyzing the mechanism of the dynamic deformation.

\section{Experimental}

The micro-alloyed HSLA steel used in this study was a $10 \mathrm{~mm}$-thick hot-rolled steel plate supplied from POSCO. The chemical composition of the steel (POSTEN55H) is shown in Table 1, and the shape of the specimen for the compres-

\footnotetext{
* ACADEMY OF CONVERGENCE EDUCATION, INHA UNIVERSITY, INCHEON, REPUBLIC OF KOREA 
sion test was cylindrical with a radius of $8 \mathrm{~mm}$ and a height of $12 \mathrm{~mm}$. The compression tests were carried out at elevated temperatures using a thermecmaster system (Fuji Electric Co., Ltd, THERMECMASTER-Z, Japan) with a range of $923 \mathrm{~K}$ to $1,223 \mathrm{~K}$ in steps of $100 \mathrm{~K}$ and strain rates of $1.0 \mathrm{~s}^{-1}$ and $0.002 \mathrm{~s}^{-1}$. Before starting the test, the specimen was remained inside the chamber for 10 minutes to stabilize the temperature. A barreling effect appeared as the compression increased. Fig. 1 shows the appearance of specimens after compression of $30 \%, 50 \%$ and $65 \%$. However, no cracks or fractures were observed during the compression test for all temperatures and strain rates.

TABLE 1

Chemical composition of micro-alloyed HSLA steel (wt. \%)

\begin{tabular}{|c|c|c|c|c|c|c|c|c|c|}
\hline \hline $\begin{array}{c}\text { Alloying } \\
\text { element }\end{array}$ & $\mathbf{C}$ & $\mathbf{S i}$ & $\mathbf{M n}$ & $\mathbf{P}$ & $\mathbf{A l}$ & $\mathbf{N b}$ & $\mathbf{T i}$ & $\mathbf{V}$ & $\mathbf{F e}$ \\
\hline wt. $\%$ & 0.17 & 0.45 & 1.50 & 0.01 & 0.04 & 0.05 & 0.01 & 0.07 & $\mathrm{Bal}$ \\
\hline
\end{tabular}

10

Fig. 1. Appearance of specimens after compression of $30 \%, 50 \%$ and $65 \%$

The isothermal compression test was performed by reaching $65 \%$ of the maximum height reduction, and the flow stress was recorded as a function of the strain for each deformation temperature and strain rate during the test. This experimental data was used to calculate the strain hardening coefficient, strain rate sensitivity $(m)$, strength coefficient, and activation energy $(Q)$.

\section{Results and discussion}

\subsection{Effect of temperature and strain rate on the flow stress}

A series of typical true stress-strain curves were obtained at various temperatures and strain rates, as shown in Fig. 2. When the temperature increased, the flow stress for both strain rates decreased, and the flow stress also decreased as the strain rate decreased at a specific temperature. The slow strain rate and high temperature provide a longer time for the energy to accumulate and a higher mobility for nucleation. Dynamically recrystallized grain growth and dislocation annihilation are facilitated, which lead to a reduction in the flow stress [6].

Fig. 2(a) shows the distinctive regions observed in the flow stress curves when tested at the $0.002 \mathrm{~s}^{-1}$ strain rate. A linear elastic region was present before the yield point, and a short range of a strain-hardening curve was followed by a plateau as
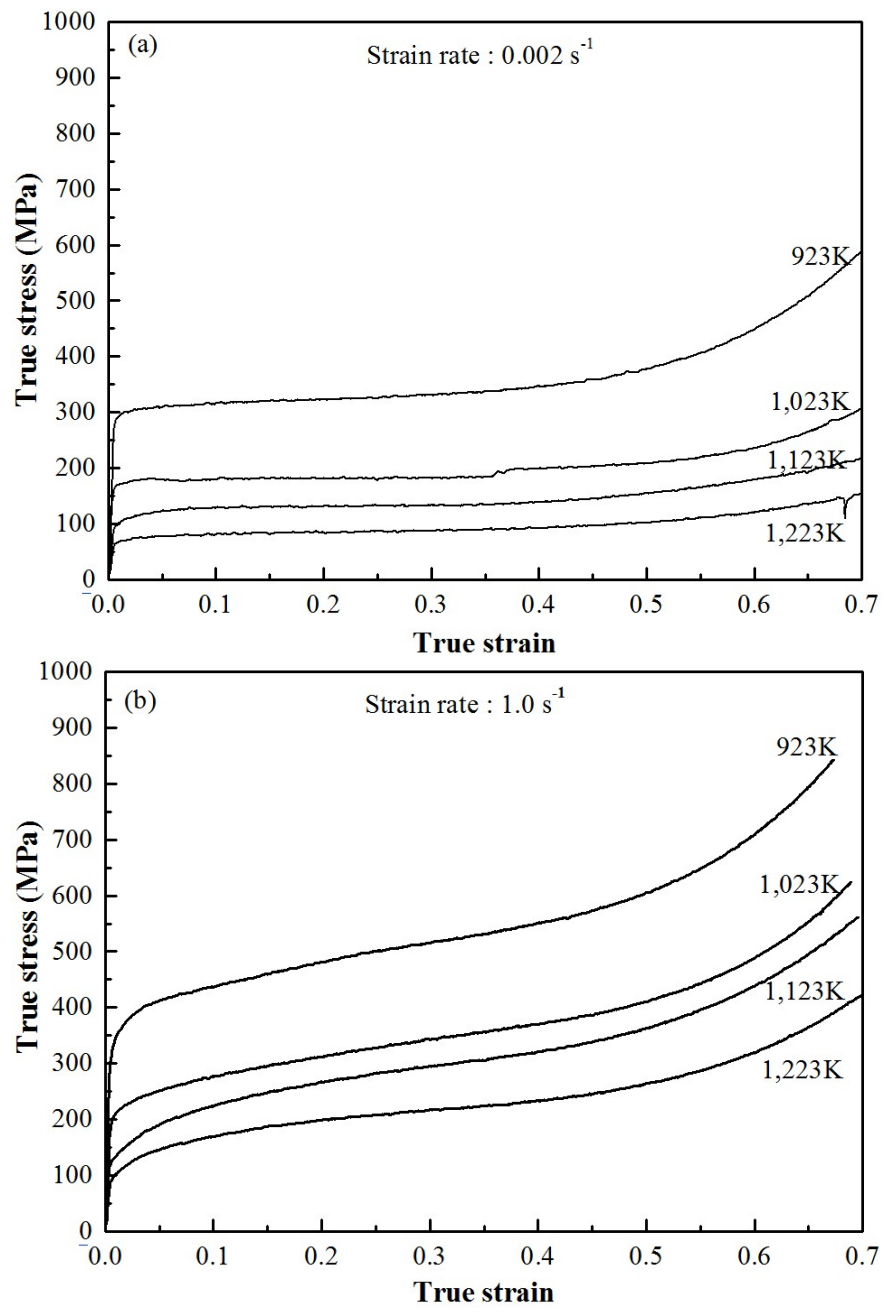

Fig. 2. True stress - true strain curves of micro-alloyed steel at various temperatures with strain rates of (a) $0.002 \mathrm{~s}^{-1}$ and (b) $1.0 \mathrm{~s}^{-1}$

the deformation proceeded. Further deformation at a strain of 0.6 led to an increase in the flow stress, which was due to the densification of the specimen during the compression test. In general, the plateau becomes larger at higher temperatures, and the initial strain hardening is associated with an increase in the dislocation density from the plastic deformation, and the formation of poorly developed sub-grain boundaries as a result of work hardening and dynamic recovery [6]. The stress achieves a steady state when a new balance between softening and hardening is obtained in the plateau $[7,8]$.

The plateau was absent in the flow stress curves when the sample was compressed with a $1.0 \mathrm{~s}^{-1}$ strain rate, as shown in Fig. 2(b). Instead, the flow stress gradually increased after the yield point, due to strain hardening. A rapid increase in the flow stress appeared as a result of the densification of the specimen when the deformation proceeded at a strain of over 0.5 . For other alloys, a hot compression test with a strain rate of $1.0 \mathrm{~s}^{-1}$ produced a region with a decrease in the stress, but no change in the stress region was observed for the Ni-V-Ti micro-alloyed steel plate. The active annihilation of the dislocations induced a decrease in the flow stress through the migration of high angle grain boundaries, once the critical strain was exceeded. The pin- 
ning effects for the dislocation movement are thus influenced by the micro-alloying elements, which leads to an increase in the stress of micro-alloyed steel plates.

The flow stress curve varies depending on the process parameters since the dynamic recovery and the recrystallization that are followed by microstructural evolution occur during hot deformation. The competing process of the deformation mechanism will proceed at elevated temperatures when recrystallization is active [9].

Fig. 3 shows the stress obtained at a strain of 0.4 as a function of temperature and strain rate. The graph indicates that the stress at a strain rate of $1.0 \mathrm{~s}^{-1}$ significantly decreased, especially when the temperature increased from $923 \mathrm{~K}$ to $1,023 \mathrm{~K}$ and from $1,123 \mathrm{~K}$ to $1,223 \mathrm{~K}$. Similar characteristics for the stress were also found at a strain rate of $0.002 \mathrm{~s}^{-1}$, when the temperature increased from $923 \mathrm{~K}$ to $1,023 \mathrm{~K}$. The temperature increased in steps of $100 \mathrm{~K}$. However, the internal deformation behavior can be concluded to have varied for each temperature region due to the difference in the stress drops. Other studies have reported that the drop in the level of stress becomes smaller at temperatures higher than $1,273 \mathrm{~K}$ due to the dominant deformation behavior of the active dynamic recrystallization.

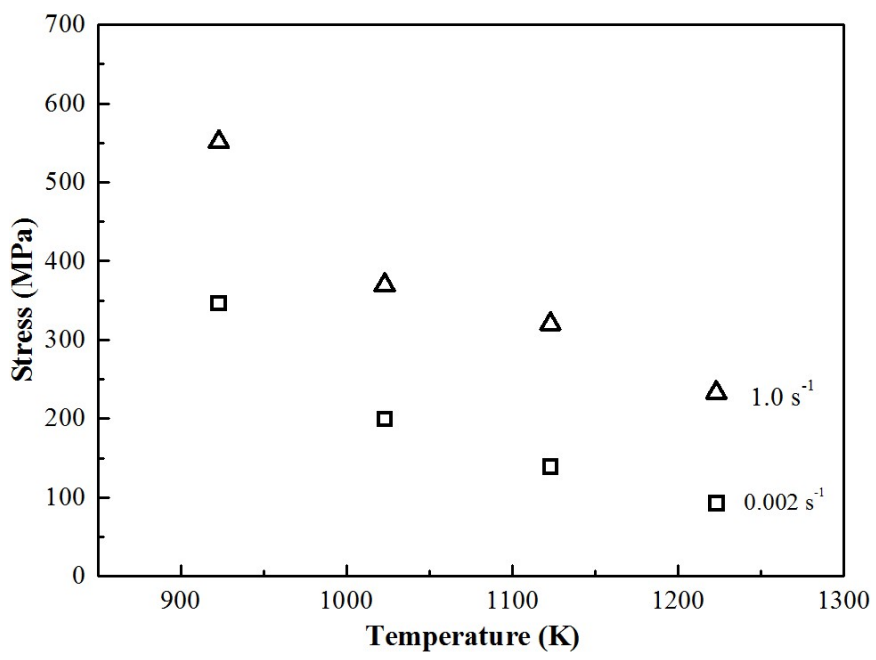

Fig. 3. Stress at a strain of 0.4 for different temperatures and strain rates

The flow stress of the materials depends on the process parameters, including the strain rate, strain, and deformation temperature. The mechanical behavior of the forming process is generally described by the following power law relation between the stress, strain, and strain hardening coefficient [10]:

$$
\sigma=K \cdot \varepsilon^{n}
$$

where $K$ is a material constant and $n$ is the strain hardening exponent.

The material parameters of $K$ and $n$ are normally determined with the experimental true stress-true strain data. Fig. 4 shows the strain hardening coefficient $(n)$ along with the different temperatures and strain rates calculated as the slope of the log scale of the stress and the strain. The graph confirmed that $n$ was dependent on the deformation temperature and the strain rate.
At a strain rate of $1.0 \mathrm{~s}^{-1}, n$ increased as temperature reached up to $1,123 \mathrm{~K}$. At a temperature of $1,223 \mathrm{~K}$, however, the $n$ value decreased to lower than that at $1,123 \mathrm{~K}$. On the contrary, the $n$ values at a strain rate of $0.002 \mathrm{~s}^{-1}$ decreased in small amounts until the temperature reached $1,123 \mathrm{~K}$ and increased at a temperature of $1,223 \mathrm{~K}$. The $n$ values that were obtained generally became smaller as the temperature increased due to softening. The results that showed an increased $n$ at a strain of $1.0 \mathrm{~s}^{-1}$ can be potentially attributed to the grain growth under the high temperature condition and to the increase in the dislocation density due to the fast strain rate. In addition, the micro-alloying elements caused a complicated interaction in the dislocation movement and grain growth.

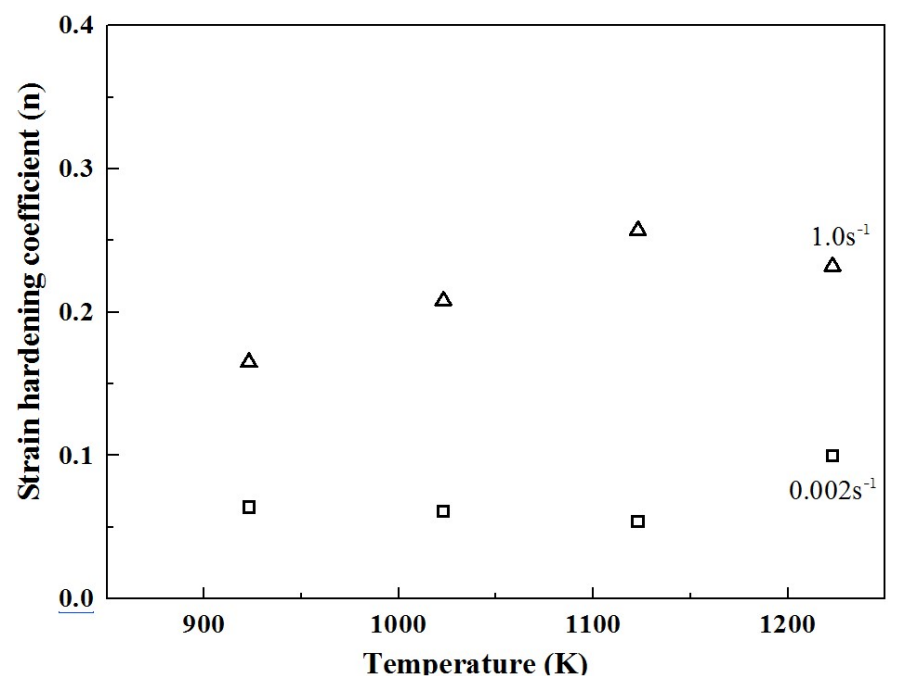

Fig. 4. The variation in the strain hardening coefficient under different temperatures and different strain rates

Fig. 5 shows the strength coefficient $(K)$, the different temperatures, and the strain rates, which were calculated using the logarithmic graph of the stress and strain curves. The $K$ values that were obtained are smaller at a higher temperature and at a slower strain rate due to the decrease in the flow stress.

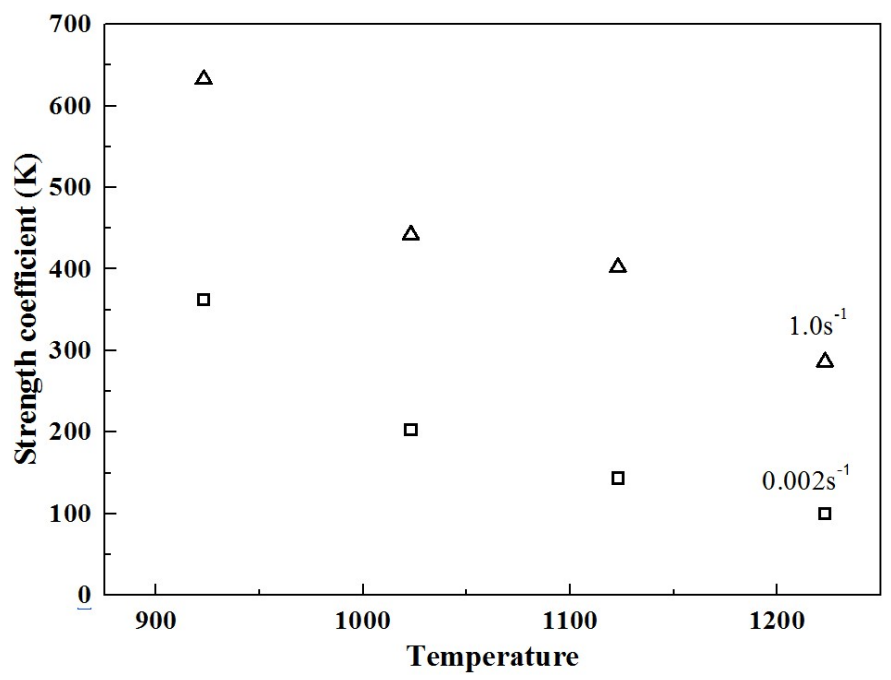

Fig. 5. The variation in the strain hardening coefficient under different temperatures and at different strain rates 


\subsection{Activation energy measurement for the micro-alloyed HSLA steel}

The dependence in the flow stress on the deformation temperature and strain rate at high temperature is generally expressed in terms of a kinetic equation given by Eq. (2) [10]:

$$
\dot{\varepsilon}=A \cdot \sigma^{n} \exp \left(\frac{-Q}{R \cdot T}\right)
$$

where $A$ is a material constant, $\dot{\varepsilon}$ is the strain rate $\left(\mathrm{s}^{-1}\right), \sigma$ is the flow stress (MPa), $Q$ is the activation energy $\left(\mathrm{J} \cdot \mathrm{mol}^{-1}\right)$ of the deformation, $\mathrm{R}$ is the universal gas constant $\left(8.314 \mathrm{~J} \cdot \mathrm{mol}^{-1} \cdot \mathrm{K}^{-1}\right)$, $T$ is the absolute temperature $(K)$, and $n$ is $1 / m$, which is the inverse value of strain rate sensitivity index.

The kinetic parameters, strain rate sensitivity index $(m)$ and $Q$, are to be evaluated in order to identify the high temperature deformation mechanism. The strain rate sensitivity index, $m$, is the most critical parameter to characterize the hot deformation. The $m$ value is a function of the forming parameters, such as strain rate and the temperature, and it is also associated with the microstructural characteristics of the material [11]. The strain-rate exponent, or $m$, characterizes the variation in the flow stress, and it can be interpreted as the slope of a graph of $\ln \sigma$ as a function of $\ln \dot{\varepsilon}$ :

$$
\sigma=\sigma_{0}\left(\frac{\dot{\varepsilon}}{\dot{\varepsilon}_{0}}\right)^{m}
$$

where $\sigma_{0}$ is the flow stress at a strain rate of $\dot{\varepsilon}_{0}$.

The $m$ values are calculated along the strain in Fig. 6, which shows larger values at higher temperatures and at an increased strain. The larger values for $\mathrm{m}$ facilitated the plastic deformation, and the increased values for $m$ originate from the microstructural changes during high temperature deformation.

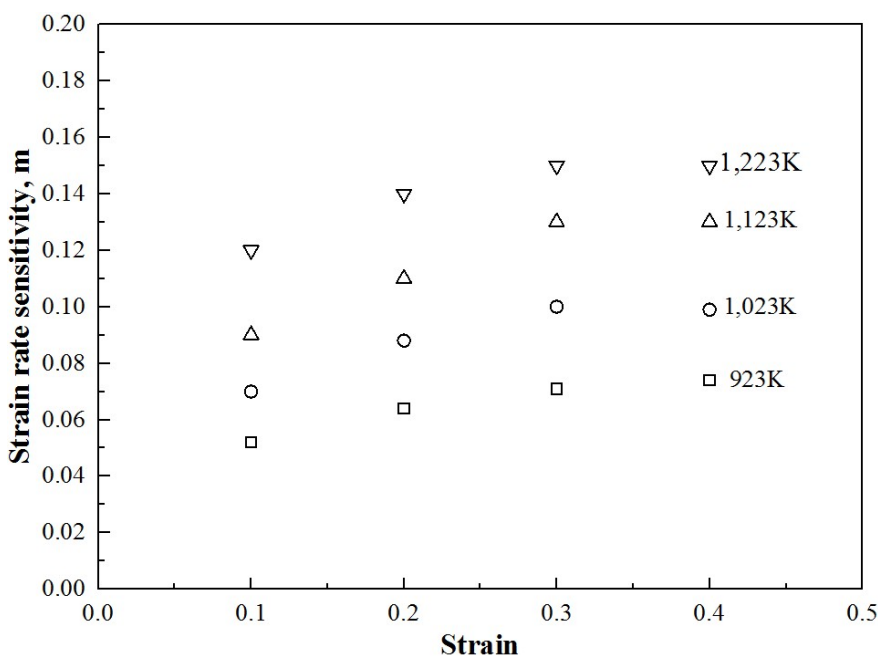

Fig. 6. Strain rate sensitivity index for various temperatures

One of the high temperature plastic deformation mechanisms is controlled through the activation process of plastic deformation. The activation energy of the deformation that represents the workability of the materials can be calculated using the Arrhenius plot of $\ln \dot{\varepsilon}$ vs. $1 / T$, which is the reciprocal absolute temperature at a constant stress, or from a plot of $\ln \sigma$ vs. $1 / T$ at a constant strain rate. The activation energy, indicated by $Q$, under a constant strain rate can be calculated with Eq. (4) deduced from Eq. (2):

$$
\ln \sigma=\frac{\ln \dot{\varepsilon}-\ln A}{n}+\frac{1}{T} \cdot \frac{Q}{R \cdot n}
$$

All of the characteristic stresses including the peak stress, steady state stress, and the stress at a specific strain are used to build the constitutive equations [12-14]. A steady state stress was not precisely achieved possibly due to the morphological evolution [15], and since the peak stress is more significant for industrial processes [16], the stress at a strain of 0.5 with an absence of densification was chosen to calculate the $Q$ values.

In Fig. 7, the slope of the $\ln \sigma$ vs $1 / T$ represents the activation energy. A strain rate of $1.0 \mathrm{~s}^{-1}$ showed an activation energy from 171 to $366 \mathrm{~kJ} \cdot \mathrm{mol}^{-1}$ for each temperature region, while that for $0.002 \mathrm{~s}^{-1}$ showed an activation energy from 270 to $578 \mathrm{~kJ} \cdot \mathrm{mol}^{-1}$. The value for $m$ was larger at a faster strain rate and smaller at a slower strain rate. Hence, the activation energy calculated for a value of $m$ of 0.15 for the $1.0 \mathrm{~s}^{-1}$ strain rate and a value of 0.07 for the $0.002 \mathrm{~s}^{-1}$ strain rate were $366 \mathrm{~kJ} \cdot \mathrm{mol}^{-1}$ and $270 \mathrm{~kJ} \cdot \mathrm{mol}^{-1}$, respectively.

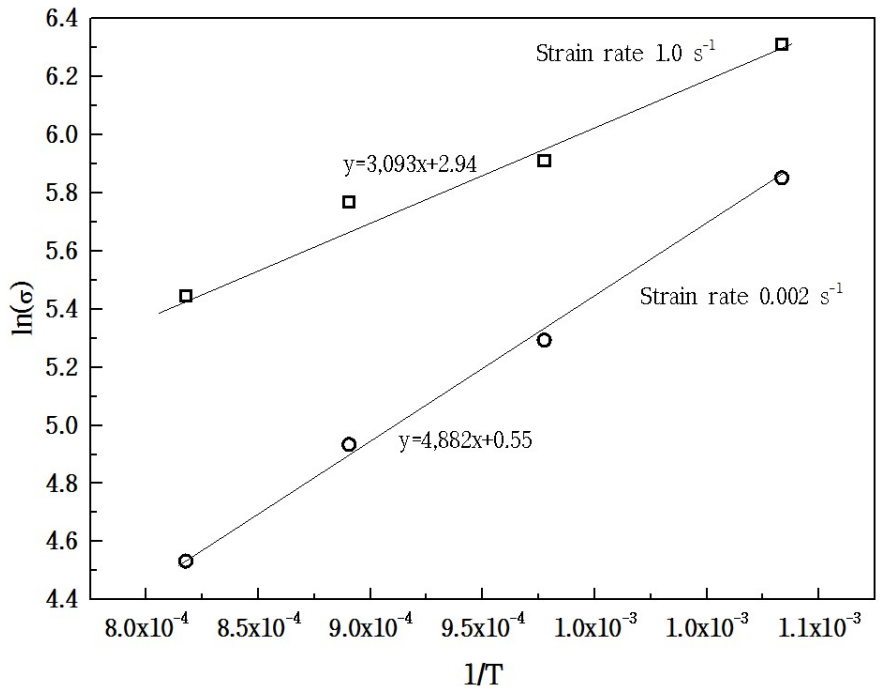

Fig. 7. Measured and linearly fitted values between $\operatorname{lns}$ and $1 / T$

The deformation is controlled by the climb in the dislocation in the matrix through the recovery that depends on the self-diffusion at an activation energy of $270 \mathrm{~kJ} \cdot \mathrm{mol}^{-1}$ for $\alpha$-Fe steel, and a larger activation energy allows for the deformation of the matrix, precipitation of the particles, and climb in the dislocation occur simultaneously. In particular, the grain boundary sliding (GBS) is the main behavior for the deformation with selfdiffusion, in which GBS is known as a source of superplasticity. The large range in the steady state stress region as a characteristic of the superplastic material was possibly caused by GBS, considering the activation energy of $270 \mathrm{~kJ} \cdot \mathrm{mol}^{-1}$ for a strain rate 
of $0.002 \mathrm{~s}^{-1}$ in a micro-alloyed HSLA steel. Other reports have confirmed that the micro-alloyed HSLA steel at a temperature range of $1,173 \mathrm{~K}-1,373 \mathrm{~K}$ with a strain rate of $0.01 \mathrm{~s}^{-1}-10.0 \mathrm{~s}^{-1}$ had the activation energy of $402 \mathrm{~kJ} \cdot \mathrm{mol}^{-1}$, which was much higher than that of conventional carbon steel $\left(280-300 \mathrm{~kJ} \cdot \mathrm{mol}^{-1}\right)$ $[17,18]$. The higher activation value can originate from the solute drag effect by pinning of the micro-alloyed elements, such as $\mathrm{Nb}, \mathrm{V}$, and $\mathrm{Ti}$ [19]. The micro-alloyed elements prohibited the uniform recrystallization at a fast strain rate, which resulted in high activation energy.

\subsection{Constitutive equation for hot compressive deformation}

The material constant, $K$, and the strain hardening coefficient, $n$, are a function of the temperature and strain rate at a high temperature, thus the constitutive equation (Eq. 5) is expressed by the Zener-Hollomon parameter $(Z)$, which is the temperature compensated strain rate parameter.

$$
\sigma=K(Z) \cdot \varepsilon^{n(Z)}
$$

Zener et al. [20] investigated the effects of the strain rate and temperature on the hot deformation, which was expressed by the Zener-Hollomon parameter in an exponential equation (Eq. 6).

$$
Z=\dot{\varepsilon} \exp \left(\frac{Q}{R \cdot T}\right)
$$

Fig. 8 shows the relation between the strain hardening coefficient, $n$, and $\ln (Z)$ with a fitted linear line for each strain rate. The $n$ value decreased linearly as the $Z$ value increased, and the relation between the strength coefficient $(K)$ and $\ln (Z)$ was shown in Fig. 9, in which the $K$ value can be seen to increase linearly as the $Z$-value increased. The changes in the flow stress of the material model during hot deformation are affected by the internal state, which is primarily determined by its structure. Furthermore, the actual response of the material to the deformation conditions

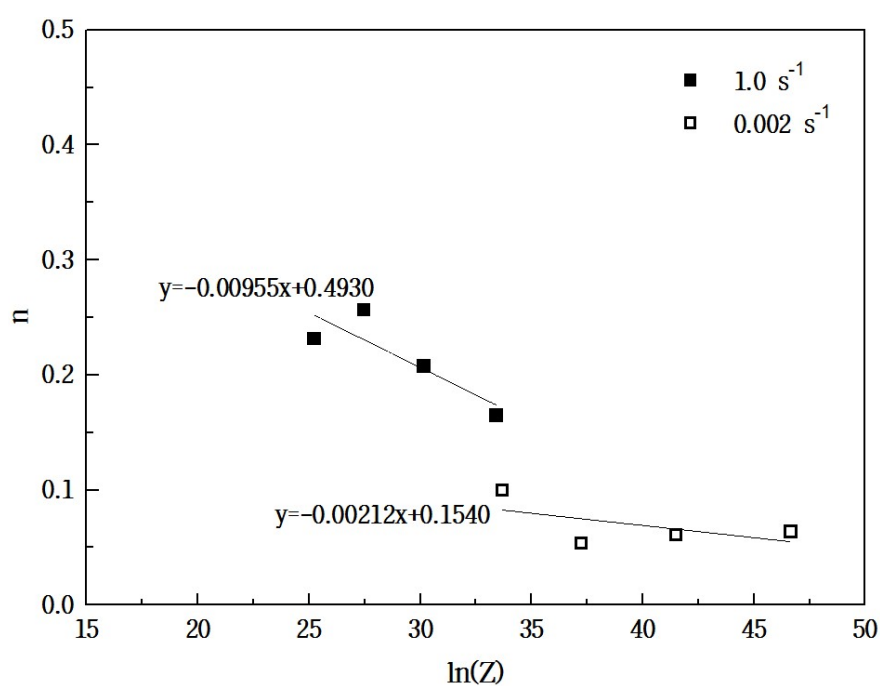

Fig. 8. The relation of $n$ with $\ln (Z)$ at strain rates of $1.0 \mathrm{~s}^{-1}$ and $0.002 \mathrm{~s}^{-1}$ depends on its internal state $[21,22]$. The substantial difference in the deformation mechanism resulting from the greater disparity in the strain rate makes it difficult to build a single flow stress model. Thus, the constitutive equation obtained from the hot compression test can be expressed as the following equations for a strain rate of $1.0 \mathrm{~s}^{-1}$ and $0.002 \mathrm{~s}^{-1}$.

$$
\begin{aligned}
& \sigma=(39.8 \ln (Z)-716.6) \cdot \varepsilon^{(-0.00955 \ln (Z)+0.4930)} \\
& \sigma=(19.9 \ln (Z)-592.3) \cdot \varepsilon^{(-0.00212 \ln (Z)+0.1540)}
\end{aligned}
$$

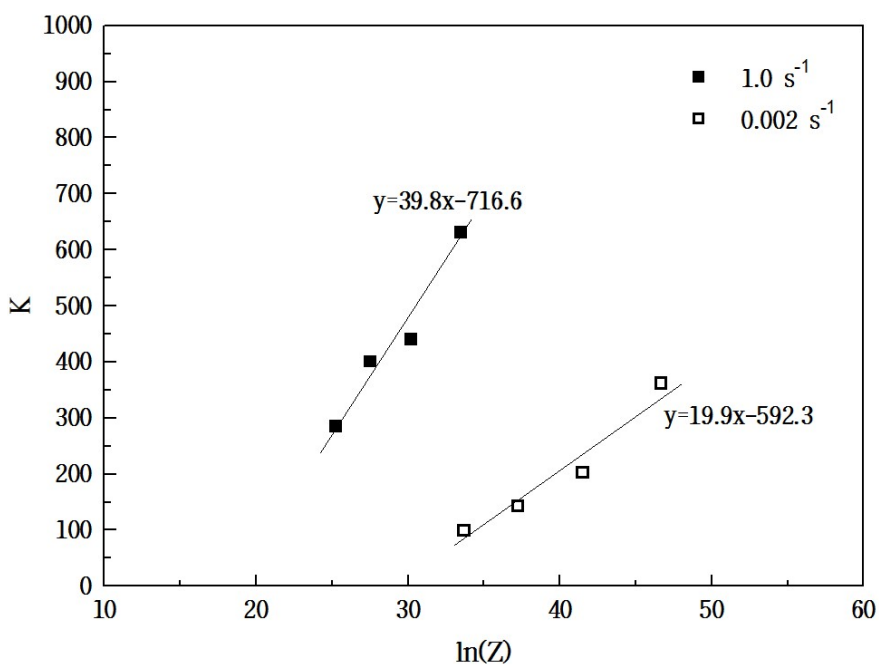

Fig. 9. The relation of the $K$ values with $\ln (Z)$ at strain rates of $1.0 \mathrm{~s}^{-1}$ and $0.002 \mathrm{~s}^{-1}$

\section{Conclusions}

A long range plateau was present at a strain rate of $0.002 \mathrm{~s}^{-1}$, which was a result of the balance between the softening and hardening during deformation. At a strain rate of $1.0 \mathrm{~s}^{-1}$, the increase in the dislocation density due to the plastic deformation and the formation of the poorly developed sub-grain boundaries resulted in a gradual increase in the flow stress after the yield point. The overall values for $n$ were larger for the $1.0 \mathrm{~s}^{-1}$ strain rate than those for the $0.002 \mathrm{~s}^{-1}$ strain rate due to the strain hardening effect. The $K$ values were smaller at a higher temperature due to the decrease in the flow stress at a slower strain rate. The activation energy for the deformation of the micro-alloyed HSLA steel at a strain rate of $1.0 \mathrm{~s}^{-1}$ and $0.002 \mathrm{~s}^{-1}$ were $366 \mathrm{~kJ} \cdot \mathrm{mol}^{-1}$ and $270 \mathrm{~kJ} \cdot \mathrm{mol}^{-1}$, respectively. The former indicated that microalloyed elements might prohibit the uniform recrystallization, resulting in strain hardening, and the latter presented a large steady state stress region that was potentially caused by GBS. Both the $n$ and $K$ values showed a linear relation with $\ln (Z)$. The constitutive model for the flow stress of heavy micro-alloyed HSLA steel plates at the strain rate of $1.0 \mathrm{~s}^{-1}$ and $0.002 \mathrm{~s}^{-1}$ can be expressed as follows:

- $\quad \sigma=(39.8 \ln (Z)-716.6) \cdot \varepsilon^{(-0.00955 \ln (Z)+0.4930)}$

$-\quad \sigma=(19.9 \ln (Z)-592.3) \cdot \varepsilon^{(-0.00212 \ln (Z)+0.1540)}$

Fig. 8. The relation of $n$ with $\mathrm{ln}(Z)$ at strain rates of $1.0 \mathrm{~s}^{-1}$ and $0.002 \mathrm{~s}^{-1}$ 
1196

\section{REFERENCES}

[1] Y.N. Kwon, Y.S. Lee, J.H. Lee, J. Mater. Process. Tech. 187-188, 533 (2007)

[2] G. Jha, S. Das, S. Sinha, A. Lodh, A. Haldar, Mater. Sci. Eng. A 561, 394 (2013)

[3] H.L. Yi, P. Chen, Z.Y. Hou, N. Hong, H.L. Cai, Y.B. Xu, D. Wu and G.D. Wang, Scripta. Mater. 68, 370 (2013).

[4] A. Gavrus, E. Massoni, J.L. Chenot, J. Mater. Process. Tech. 60, 447 (1996)

[5] Z. Gronostajski, J. Mater. Process. Tech. 106, 40 (2000).

[6] K. Wu, G.Q. Liu, B.F. Hu, C.Y. Wang, Y.W. Zhang, Y. Tao, J.T. Liu, Mater. Sci. Eng. A 528, 4620 (2011).

[7] T. Sakai, J.J. Jonas, Acta Metall. 32, 189 (1984).

[8] H.J. McQueen, Mater. Sci. Eng. A 387-389, 203 (2004).

[9] H. Wei, G. Liu, X. Xiao, H. Zhao, H. Ding, R. Kang, Mater. Sci. Eng. A 564, 140 (2013).

[10] M. Li, H. Pan, Y. Lin, J. Luo, J. Mater. Process. Tech. 183, 71 (2007).
[11] P.A. Friedman, W.B. Copple, J. Mater. Eng. Perform. 13, 335 (2004).

[12] S. Mandal, V. Rakesh, P.V. Sivaprasad, S. Venugopal, K.V. Kasiviswanathan, Mater. Sci. Eng. A 500, 114 (2009).

[13] H. Yang, Z. Li, Z. Zhang, J. Zhejiang Univ-SC. A 7, 1453 (2006).

[14] H.T. Zhao, G.Q. Liu, L. Xu, Mater. Sci. Eng. A 559, 262 (2013).

[15] H.J. McQueen, N.D. Ryan, Mater. Sci. Eng. A 322, 43 (2002).

[16] H. Mirzadeh, A. Najafizadeh, M. Moazeney, Metall. Mater. Trans. A 40, 2950 (2009).

[17] B. Kowalski, C.M. Sellars, M. Pietrzyk, ISIJ Int. 40, 1230 (2000).

[18] W.P. Sun, E.B. Hawbolt, ISIJ Int. 37, 1000 (1997).

[19] J.H. Yang, Q.Y. Liu, D.B. Sun, X.Y. Li, J. Iron Steel Res. Int. 16, 75 (2009).

[20] C. Zener, J.H. Hollomon, J. Appl. Phys. 15, 22 (1944).

[21] Z. Marciniak, A. Konieczny, J. Mech. Work. Technol. 399, 15 (1987).

[22] Z.J. Gronostajski, Z. Misiolek, Arch. Metall. 40, 399 (1995). 